\title{
Enhancing community role in catchment area of cascade-pond system at the campus of Universitas Indonesia, Depok, West Java, Indonesia
}

\author{
Caya Maitri ${ }^{1, *}$, Dwita Sutjiningsih ${ }^{1}$, and Evi Anggraheni ${ }^{1}$ \\ ${ }^{1}$ Civil Engineering Department, Universitas Indonesia, 16424 Depok, Indonesia
}

\begin{abstract}
The population in the catchment area of Universitas Indonesia (UI) campus cascade-pond system is growing rapidly. The rapid growth of population increases the activities intensity in the catchment area, so that a better water resource management is urgently needed. The Dublin Principles in Integrated Water Resource Management (IWRM) among others says that water development and management should be based on a participatory approach, which involves users, planners and policymakers at all levels. The Watershed Stewardship Program is one of the Eight-Tool for Watershed Protection developed by Center for Watershed Protection. Community as the main role holder, besides as beneficiary, is also as planner and executor of the program. The study aims to facilitate community in designing the activities towards water-friendly neighborhood, in the framework of community-potential-based watershed management, to increase the health of UI aquatic system and its catchment area. A combination of Participatory Action Research and Appreciative Inquiry method is applied. The required data and information is collected through field survey and focus group discussion (FGD). Field survey is conducted by interviewing random population inside the catchment area to get the behavior pattern overview of the community. FGD aims to unite the stakeholder and discuss their knowledge and potencies.
\end{abstract}

\section{Introduction}

In this globalization era, especially in Indonesia as a developing country, there are many things that are being developed in every sector. Development is closely related to construction project. Construction project has its own advantages and disadvantages. The advantages of the construction project are definitely what the purpose of the construction. Besides, it decreases the total area of the pervious cover of land. Watershed is an area of land which is bounded by topographic separation and shore, and it is influenced by the activity of the area [1]. Watershed is divisible into a number of catchment areas. It eases community to maintain their own little catchment area by their own ability and potencies. Regencies became the first rank of land cover in the catchment area of cascade-pond system at the campus of UI. The outlet of cascade pond system at campus of UI is midCiliwung watershed. The catchment area of cascade-pond system at campus of UI includes 6 villages (Kukusan, Beji, East Beji, Depok, Depok Jaya, and Kemiri Muka) and a little

* Corresponding author: caya.maitri@ui.ac.id 
part of Pondok Cina and Pancoran Mas village. There are 6 cascade-ponds in UI Campus (Kenanga, Agathis, Mahoni, Puspa, Ulin, Salam).

Center for Watershed Protection define eight tools of watershed protection in developing areas, one of them is Watershed Stewardship Program [2]. One of principles applied in Integrated Water Resources Management (IWRM) is Dublin Principles. One of these principles is that Water resources development and management should be based on a participatory approach, involving all relevant stakeholders $[3,4]$. Those statements implied that there should be the nearest stakeholders to participate in protecting and managing the watershed. That place is best filled by its own community, especially in this study case, because the community takes the most intervention in the catchment. In this study, Appreciative Inquiry (AI) is applied to strengthen the community role. AI is about the coevolutionary search for the best in people, their organizations, and the relevant world around them. Four stages in AI: Discovery-mobilizing a whole system inquiry into the positive change core; Dream-creating a clear result-oriented vision in relation to discovered potential and in relation to questions of higher purpose; Design-creating possibility proportions of the ideal organization, an organization design which people feel is capable of magnifying or eclipsing the positive core and realizing the articulated new dream; and Destiny — strengthening the affirmative capability of the whole system enabling it to build hope and momentum around a deep purpose and creating processes for learning, adjustment, and improvisation like a jazz group over time [5]. This study is a Participatory Action Research (PAR). PAR means an action research that needs objects participation. The use of AI changes the role of object, in this study is community, become partner. PAR is generally thought to involve a spiral of self-reflective cycles of Planning-Acting and Observing-Reflecting-Replanning-Acting and Observing again- and so on [6].

Participation potency of community in the catchment of cascade-pond system at UI campus is actually good. The awareness of environment cleanliness is a very basic thing to be acculturated in community. This can be started from their neighborhood, sub-village, village, to sub-district government. In Beji sub-district, which parts of them included in the catchment of cascade-pond system at UI Campus, always conduct a Jumsih (Clean Friday) event every Friday to keep the environment clean so that they can maximize their service to the community. This event also gives motivation to the community to actively participating in keeping their environment clean.

The use of Appreciative Inquiry (AI) Approach in Participatory Action Research (PAR) to enhance community role of contributing in catchment area management is not applied yet, especially in the catchment area of cascade-pond system at the campus of Universitas Indonesia.

\section{Methodology}

This study is a Participatory Action Research (PAR) using Appreciative Inquiry (AI) approach. The method of data collecting is by surveying and discussing. Collected data from survey then extracted to get the pattern of community existing participation and potency. The output of FGD is to unite the stakeholders and discuss their knowledge and potencies. 


\subsection{Research Site}

This study takes place in the catchment of cascade-pond system at the campus of Universitas Indonesia. Following picture shows the catchment area and the name of the village.

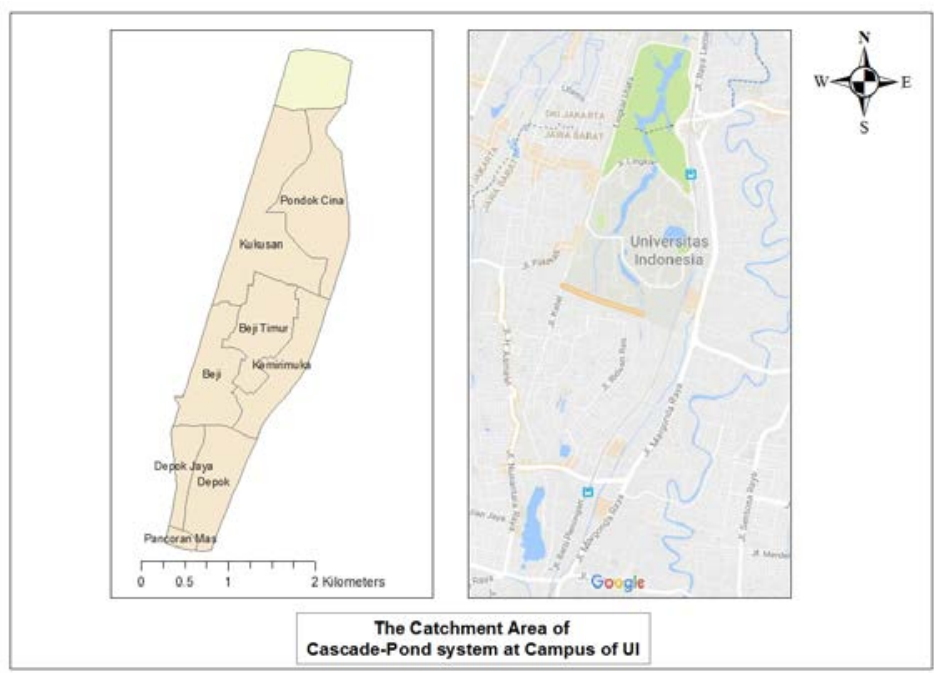

Fig. 1. The catchment area of cascade-pond system at the Campus of Universitas Indonesia.

\subsection{Survey}

There are 3 main parts of surveying, those are preparing, surveying, and post-surveying. Preparing the survey is about making the questionnaire, determining the location, and the respondents of survey and also briefing the surveyors. The questionnaire is divided into three parts; those are respondents' basic info, existing conditions, and respondents' participation potencies. Respondents' basic info contains name, address, gender, age, and latest formal education. Existing conditions contains their sanitation [7] and their existing event aiming for clean environment. Respondents' participation potencies contains if they will be participating while there's any environment protection event or not and good things they will do to their unused spaces around their house. The surveyors are divided into 7 teams which will survey different villages. The villages we chose to be surveyed are Beji, East Beji, Kemiri Muka, Pondok Cina, Depok Jaya, Kukusan, and Depok. Pancoran Mas village is not surveyed because the part which included in the catchment area is too small and consist of trading areas only. This survey doesn't plot any smaller area, so the surveyors can survey to anyone in anywhere bounded by their village area. The term postsurveying is about data recapitulating and extracts it to get the pattern of community potencies and existing participations. Extracted data show the relationship between gender, age ranges, last formal education and the existing condition and participation potencies.

\subsection{Focus group Discussion (FGD)}

The FGD had been attended by any stakeholder of the catchment of cascade-pond system at UI campus protection effort. They came from National Government, Local Government, Non-Government Organization, University, and Community Delegation. FGD started by panel discussion by the speakers from National Government to give the general 
information about catchment area health assessment. FGD continue by dividing the attendants into two main groups, decision makers and beneficiaries, those group were divided again into two groups so that we have four focus groups. After dividing the attendants into four groups then the discussion started in those groups discussing about the topic which had been made before. The materials of the discussion are their knowledge about catchment area health quality, the factors influence catchment area health quality, the stakeholders who had responsibility to catchment area quality, the effort to achieve better catchment area quality, and the way how to monitor the catchment area quality. After collecting the opinion of the attendants by discussing in four focus groups, then the attendants will reunite into two groups; Decision Makers and Beneficiaries to bring their opinion into one agreed opinion for those groups. The second discussion mastered by facilitators and helped by reporter and time keeper. After having agreed opinion then the attendants reunited in the plenary discussion. The plenary discussion aims to get the agreement of the discussion results. The result is their knowledge and awareness of catchment area protection. It is expected to trigger the community to enhance their participation in protecting the catchment area.

\section{Result and Discussion}

The result of surveying is the pattern of community's existing condition and potencies compared by their gender, age range, and latest formal education. The existing condition is about the way they drain off their grey water and black water, the way they treat their solid waste, and the existing event aiming clean environment. The potencies are about their willingness to use their unused space around their house and their willingness to actively participating in any environmental protection event. The result of FGD is their knowledge and awareness of catchment area protection.

\subsection{Survey}

Collected data from survey then extracted to see the percentage of total respondent's respond and the relationship between respondent's respond and their latest formal education, gender, and age range. Survey results then divided into three parts; Existing condition, Existing Participation, and Potencies.

\subsubsection{Existing Condition}

Existing condition contains the way they dispose waste; grey water, black water, and solid waste. Following figures show the examples of the way the dispose waste.

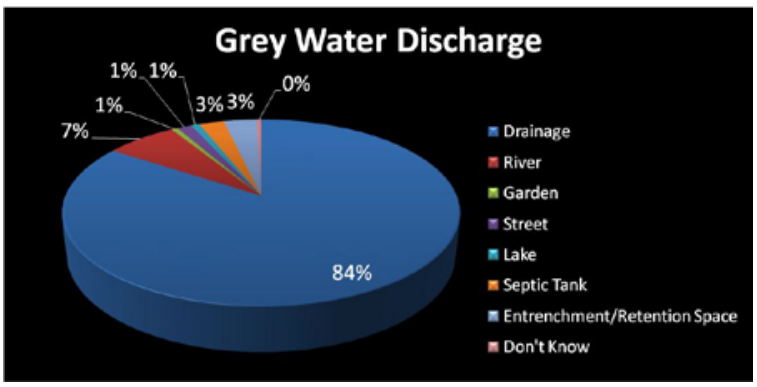

Fig. 2. Respondent's respond about the way they drain their grey water off. 


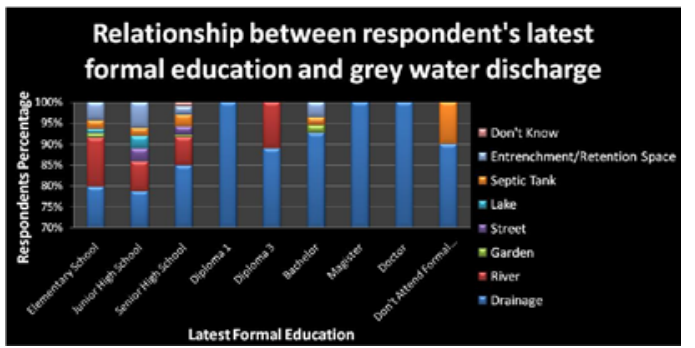

(a)

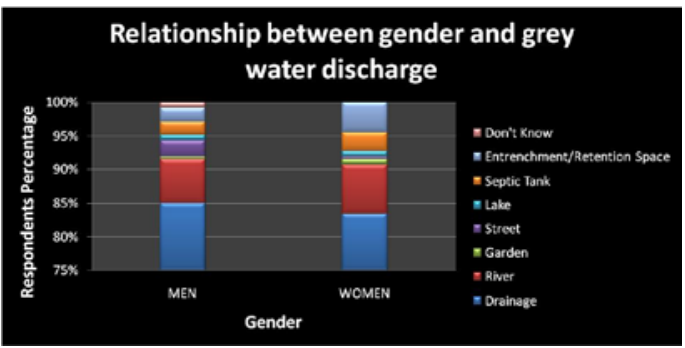

(b)

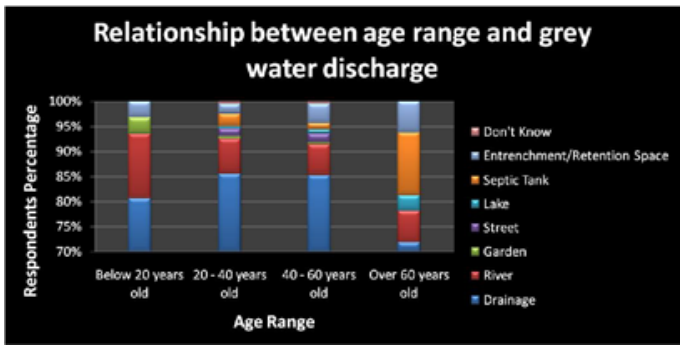

(c)

Fig. 3. Relationship between grey water discharge and respondent's (a) latest formal education; (b) gender; and (c) age range.

Grey water discharge management dominated by direct discharge to drainage with the total percentage of $84 \%$. This result shows that grey water discharge management is the same as rainfall runoff discharge system. There was no significant differences when they are classified by their gender, latest formal education, or age. The existing condition result shows the same result that gender, latest formal education and age do not change any significant differences. For black water discharge, most of member of the community already know that it is better to drain the black water off to the septic tank. Besides, there still 3\% of respondent who discharge their black water to the river without any treatment. The treatment of solid waste is dominated by paying the garbage collector to dispose it to the landfill but $10 \%$ of respondent still treat the garbage by burning it and $4 \%$ honestly say that they throw the garbage to the river.

\subsubsection{Existing Participation}

Existing participation is their participation in past event aiming clean and health environment, for example cleaning the drainage up, planting plants, restoring the street, etc. following figures show their participation in those event.

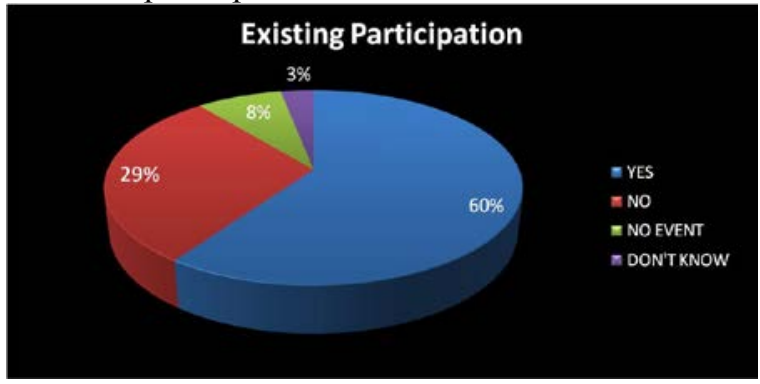

Fig. 4. Total Respondent's existing participation 


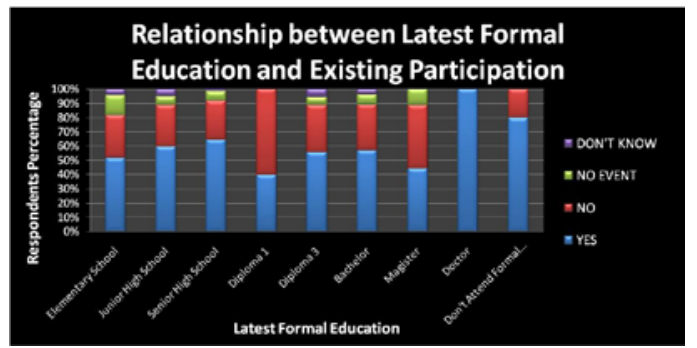

(a)

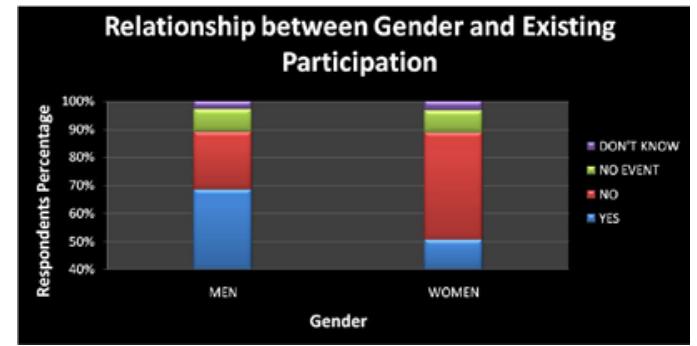

(b)

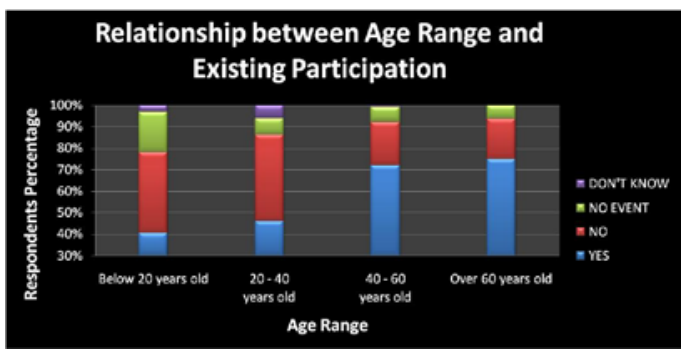

(c)

Fig. 5. Relationship between existing participation and respondent's (a) latest formal education; (b) gender; and (c) age range.

The figures show that the member of the community mostly participating in their event aiming health environment although there were $29 \%$ of the respondents who do not participating in the event and it was not a few numbers. The relationship graphs show no relation between respondent's latest formal education and their participation. The relationship between gender and their participation shows that men have the higher willingness to participate in the event because women usually do not take part in the activity but they participate in preparing the lunches and drinks. The relationship between age range and their participation show that the older their age the more they are willing to take a part in achieving better environment.

\subsubsection{Potencies}

The Potencies is their willingness to actively taking part in any event aiming clean and health environment/watershed and their willingness of functioning their unused space around their house in effort to achieve a better environment/watershed. Following figures show their willingness to actively take a part of future program.

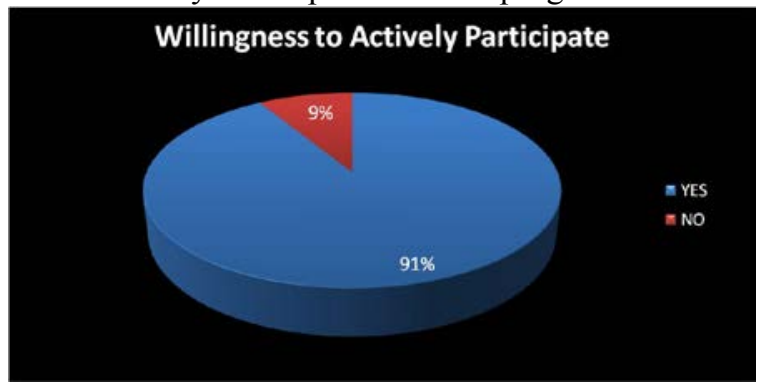

Fig. 6. Respondent's willingness to actively participating in future program. 


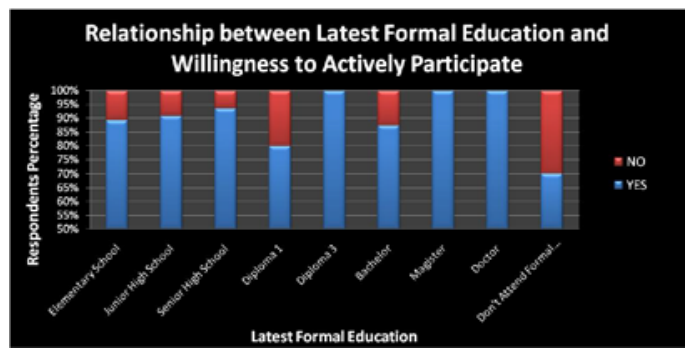

(a)

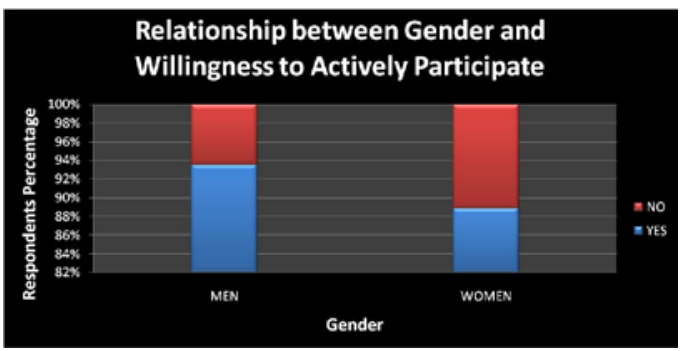

(b)

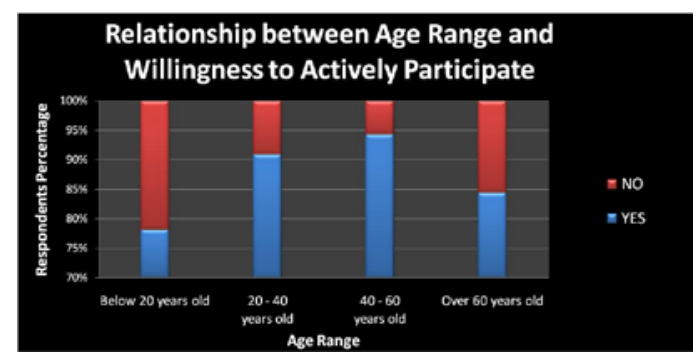

(c)

Fig. 7. Relationship between their willingness to actively take a part of future program and respondent's (a) latest formal education; (b) gender; and (c) age range.

Respondents mostly have willingness to actively participating in future program aiming clean and health environment but there is still $9 \%$ of respondents say that they do not want to actively participate. The relationship graphs show that the highest percentage of respondent who do not want to actively participate is the groups of respondents who do not attending formal education. If it compared by gender, women has the higher percentage in refusing actively participating in future program. It also shows that the older age range, the higher the percentage of respondent's willingness to actively participate in future program, but there is decreasing percentage for the age range above 60 years old. Following figure shows

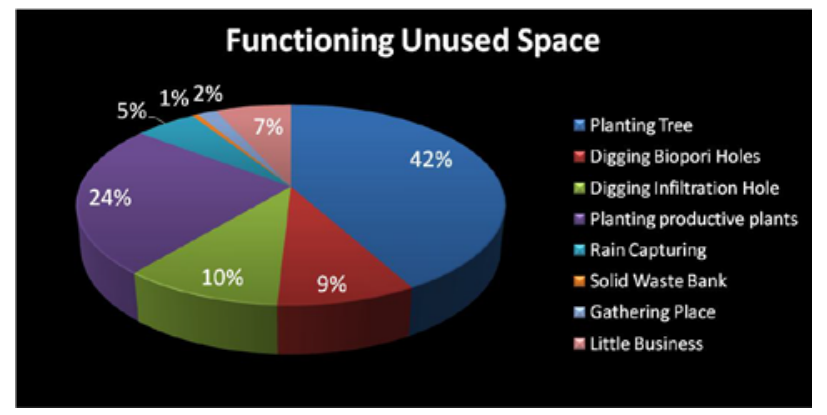

Fig. 8. Respondent's willingness to functioning their unused space around their house.

Based on the pie chart above, we can conclude that mostly the member of community want to functioning their unused space around their house by planting trees and productive plants because it is easy. They are not preferred to do another effort because they do not know the way it works. Embarrassingly, $7 \%$ of respondents still prefer functioning their unused space by building small business. 


\subsection{Focus Group Discussion (FGD)}

The first topic for discussion is about the knowledge of water and catchment area health quality and its changes possible consequences. Decision Makers team said that water health quality is when the water body is free from wastes and the consequence of its changes is human health quality. Beneficiaries team said that water body health quality is the indicator of the condition of water is good or not, it can be used to determine whether the water can be used or not in the future. Water quality changes influences water ecosystem, water resource for human or any living creature consumption, and human health.

The second topic of the discussion is about the importance of letting the water body and catchment area quality good and the factors of the quality changes. Decision Makers said that it is important to let the water body quality good and the factor of quality changes is wastes. Beneficiaries team said that it is important to let the water body quality good in order to balance the ecosystem and because it relevant to human health quality. They argue that the factors of the quality changes are wastes, water treatment, and community awareness of water quality.

The third topic is those responsible to let the environment/water body quality good. Decision Makers team said that the responsibility should be held by the government, community, and any other parties who doing activity in the catchment area. The other team states the same answer.

The forth topic is the possible effort aiming enhancing water quality they can do, the easiest effort that can be a recommendation to enhance water quality and how to do it. Decision Maker team opinion is law enforcement, criminal penalty, evaluation and monitoring in any stages, and enhancing every stakeholder awareness. They state that the easiest effort that recommended to be applied is enhancing every stakeholder's awareness by educating them from sub-neighborhood scale to higher scale. Beneficiaries team opinion is to do "Gerakan RT Ramah Air" (Sub-Neighborhood Water Friendly Movement). This movement contains counseling, solid waste treatment, partnership, non-structural approach (communication, education, rainfall and another gauges), and structural approach (urban master plan).

The last topic is about monitoring water health quality. Decision Maker team state that monitoring is needed to make sure the water quality good and do not suffer community's comfort and quality. The parties who will monitor is the government around water body, Local Department of Highways and Water Resources, and other authorized stakeholder by periodically evaluating and monitoring water quality and following up the result. Beneficiaries team state that monitoring is needed to ensure the quality is good and later the data become public database. Monitoring will be held by action monitoring.

\section{Conclusion}

The existing solid waste and black water treatment condition of the catchment area of cascade-pond system at UI campus is mostly good but there also several percent of respondent state they still have a bad habit in managing those wastes, it causes bad water quality. More than $50 \%$ of respondents said that they had been participated in their past event aiming clean and health environment, while 29\% did not participated, $8 \%$ said that there was no event aiming clean and health environment, and $3 \%$ even do not know 
whether there was an event aiming clean and health environment or not. For future event, $91 \%$ of respondents agree to actively take part in it. In determining good things to do in their unused space around their house, they mostly choose planting trees and productive plants because it is easy to apply. Through FGD, it can be concluded that actually both Decision Maker and Beneficiaries have a basic knowledge about water health quality, how to make it better, and who have responsibility to it although somehow their perception about those things still different and need a further discussion to equalize their perception. The further step of this study will be choose one neighborhood which directly flow their runoff to the cascade-pond at UI campus, build a partnership which contain every stakeholder in catchment area of the cascade-pond system at UI campus, discuss what they will do to enhance their role in managing health quality of catchment area of the cascadepond system at the campus of Universitas Indonesia, and implement the agreed activity/ program.

Acknowledgements are addressed to Universitas Indonesia for giving financial support through the PITTA 2017 funding scheme, Head of Ciliwung-Cisadane River Basin Management board, Sahroel Polontalo as a head of Ciliwung- Depok Community for giving advice and suggestion, 14 Surveyors which consist of college students and staffs of Civil Engineering Department Universitas Indonesia in conducting field survey and data input, and the community in catchment area of the cascade-pond system at the campus of Universitas Indonesia as the respondents in this study.

\section{References}

1. Ministry of Public Works and Housing, Peraturan Menteri no. 04/PRT/M/2015 (Ministry of Public Works and Housing, Jakarta, 2015)

2. H. Kwon, R. Winer, T. Schueler, Eight Tools of Watershed Protection in Developing Area http://www.epa.gov/watertrain (2016)

3. P. Borchardt, Introduction to Integrated Water Resource Management http://www.iwrm-education.de/\#!borchardt2 (2012)

4. P. Zaag, H. Savenije, Principles of Integrated Water Resource Management (UNESCO-IHE, Delft, 2014)

5. D. Cooperider, D. Whitney, A Positive Revolution in Change: Appreciative Inquiry (Berret-Koehler Publishers, Inc., California, 2005)

6. S. Kemmis, R. McTaggart, Participatory Action Research: Communicative Action and the Public Sphere (Sage Publication Ltd, California, 2007)

7. N. Lies, Laporan Pemutakhiran Studi EHRA (Pokja AMPL/sanitasi Kota Depok, Depok, 2015) 